\title{
The Australian Prevention Partnership Centre: systems thinking to prevent lifestyle-related chronic illness
}

\author{
Andrew Wilsona, Sonia Wutzke ${ }^{a, b}$ and Marge Overs ${ }^{a}$ \\ a The Australian Prevention Partnership Centre, Sydney, NSW, Australia \\ b Corresponding author: sonia.wutzke@saxinstitute.org.au
}

\section{Article history}

Publication date: November 2014

Citation: Wilson A, Wutzke S, Overs M. The Australian Prevention Partnership Centre: systems thinking to prevent lifestyle-related chronic illness. Public Health Res Pract. 2014;25(1):e2511401. doi: http://dx.doi. org/10.17061/phrp2511401

\section{Key points}

- Chronic diseases are the biggest contributor to premature death and disability in Australia

- It has been difficult to systematically implement interventions that target lifestyle-related risk factors for chronic disease

- Multilevel, multisector and whole-ofsystem approaches are required for the effective and sustained prevention of complex chronic disease

- The Australian Prevention Partnership Centre is exploring new ways to bring together researchers, policy makers and practitioners to determine the information and actions needed to prevent lifestylerelated chronic disease

\section{Abstract}

Chronic diseases are the major cause of death in Australia and the biggest contributor to premature death and disability. Although prevention of chronic disease can be effective and cost-effective, it has proven difficult to systematically implement interventions that target important lifestyle-related risk factors for chronic disease such as poor nutrition, physical inactivity and harmful alcohol use.

Prevention efforts targeting these lifestyle-related risk factors have had mixed success due to issues around designing and implementing effective interventions that address the complexity of risk factors, and incorporating evidence and implementing interventions at a scale, duration, intensity and quality required to achieve population effects. There is increasing recognition that multilevel, multisector approaches are required for the effective and sustained prevention of complex chronic disease.

The Australian Prevention Partnership Centre, one of two National Health and Medical Research Council Partnership Centres established in 2013, is researching and developing systems perspectives to prevent lifestyle-related chronic disease in Australia. The Centre's collaborative approach is providing opportunities for researchers to work with policy makers and practitioners to develop research questions, conduct research, and analyse, interpret and disseminate the findings. As such, it is the model of interaction that is being tested as much as the specific projects. With its funding partners, the Centre has developed plans for more than 30 projects. It has also established four capacity units that will improve the gathering, sharing and use of evidence to build a prevention system in Australia. The Centre is exploring new ways to advance prevention by bringing together researchers, policy makers and practitioners to determine the information and actions needed for an effective prevention system for Australia. 


\section{Increasing burden of chronic} disease

Chronic diseases are the major cause of death in Australia and the biggest contributor to premature death and disability-adjusted life years (DALYs). ${ }^{1}$ With very few exceptions, chronic disease is increasing as a determining factor in DALYs in all countries, regardless of their level of economic development. ${ }^{2}$ In Australia, as life expectancy has increased, the number of older Australians living with a chronic disease has increased. Between 1997 and 2007, the proportion of deaths reported as being caused by five or more chronic diseases increased from $11 \%$ to $21 \%{ }^{3}$

Half of all Australians aged between 45 and 64 have one or more chronic diseases. ${ }^{4}$ Compared with sameage peers, people with chronic disease are $60 \%$ more likely to not participate in the labour force, are less likely to be employed full time, and are more likely to be unemployed than people without chronic disease. ${ }^{5}$ If we want to reduce the burden of chronic disease, improve productivity and live our longer lives in good health, there is clearly a need for prevention.

Given this complex profile, it is easy to be nihilistic about preventing chronic disease. While complex prevention interventions have proven difficult to evaluate (as highlighted in the article in this issue by Bauman and Nutbeam), there is high-quality evidence that prevention of chronic disease is effective and cost-effective. ${ }^{6}$ Moreover, these impacts can be influential at a population level. One example is the extraordinary decline in mortality from ischaemic heart disease, which has more than halved since 1967. ${ }^{7}$ Prevention efforts such as smoking controls, and hypertension and hyperlipidaemia detection and treatment have been major contributors to this decline. ${ }^{8}$

However, these were probably the 'easy wins' in prevention. It has proven much more difficult to systematically implement interventions that target important lifestyle-related risk factors for chronic disease such as poor nutrition, physical inactivity and harmful alcohol use. Also, it has been difficult to address the socioeconomic differentials in health and risk factors for chronic disease. Even when interventions have been demonstrated to be effective in specific research settings, there are few examples of successful population-wide implementation.

In our view, at least five major factors are contributing to the mixed record of success of preventive interventions that target lifestyle-related risk factors for chronic disease:

- The challenge of designing, funding and implementing multistrategy interventions that address the complexity of risk factors for chronic disease

- The implementation of simple, independent, oneoff solutions that are not suitable for long-lasting, sustainable change
- The failure to identify and incorporate evidence and experience of what does or does not work in designing and implementing initiatives, including replication and dissemination of effective interventions - the frequently recognised evidence-research gap ${ }^{9,10}$

- The fact that many interventions are not implemented at a scale, duration, intensity and quality likely to achieve sustainable population effects ${ }^{11-14}$

- The prevalence of evaluations that are overly simplistic and unable to fully appreciate the inputs and effects of initiatives.

\section{Call for systems approaches}

Internationally, there is increasing recognition that multilevel, multisector approaches are required for the effective and sustained prevention of complex chronic disease. It is not enough to simply urge Australians to eat better and exercise more - we need to look in depth at our communities, our food systems, our environments and our workplaces, and assess how these interact to create communities in which healthy choices are the easier, more sustainable choices.

To achieve this, prevention science is increasingly looking to systems science for different ways to develop, implement and evaluate interventions. Systems science provides a way to examine complex problems, taking into account the bigger picture and context of those problems. It includes:

- Conceptualising and mapping all the parts and interrelated elements of the issue, with an appreciation that a system is more than the sum of its parts (developing systems maps)

- Examining potential leverage points for changing the issue and testing the outcomes, both positive and negative, from different intervention options (modelling and scenario testing)

- Identifying approaches to influence the issue that recognise the complexity of the system (developing management strategies)

- Implementing changes to influence the issue, and reflecting on effects and revising strategies (feedback and reflection).

Prevention science also has many overlaps with the growing field of implementation science.

\section{The Australian Prevention Partnership Centre}

The Australian Prevention Partnership Centre is similar to successful models used internationally, such as the Population Health Intervention Research Initiative for Canada. ${ }^{15}$ The Centre was established in July 2013 to research and develop systems perspectives to prevent lifestyle-related chronic disease in Australia. 
It is one of two National Health and Medical Research Council (NHMRC) Partnership Centres launched in 2013 to improve the availability and quality of research evidence for policy decision makers. The NHMRC, the Australian Government Department of Health, NSW Ministry of Health, ACT Health and the HCF Research Foundation have provided the Centre with \$22.6 million over five years.

The Centre is administered by the Sax Institute in Sydney and co-hosted by the Sax Institute and the Centre of Excellence in Intervention and Prevention Science in Melbourne.

The team includes many of Australia's international lead researchers and practitioners in prevention, with 31 investigators from five states and territories representing more than 20 research institutes, and government, non-government and private sector agencies. The investigators are champions of developing evidence from research, implementing researchinformed changes to policy and practice, and developing innovative research methods. The inclusion of such a large and diverse group is intended to facilitate connections in research in chronic disease prevention, and to reflect the range of agencies that need to be involved outside the health sector. It is likely that the Centre's activities will lead to more groups that are directly or indirectly involved with its work being able to achieve meaningful and sustainable change.

\section{Objectives and approach}

The Centre's priority areas are the main lifestyle-related determinants of chronic disease risk: obesity, diet, tobacco, physical activity and alcohol. However, the Centre is not limited in its scope and will draw on relevant research and practice from any field that will potentially advance thinking, such as knowledge and experience gained in the fields of HIV prevention, motor vehicle accidents and Indigenous health.

The Centre's specific objectives (Box 1) are intended to capture the broader objectives of the NHMRC program. ${ }^{16}$ As articulated by the NHMRC, Partnership Centres are intended to be fundamentally different to other NHMRC research programs through:

- A focus on research-informed change in practice, management or policy as the driving force behind activities, including the determination of a centre's priority theme by health or healthcare system organisations, rather than by researchers

- A recognition that investigators are not only researchers. System-based clinicians, managers or policy makers who bring skills other than research analysis and methods to the Partnership Centre equally qualify as investigators, and are central to the work of the Centre
Box 1. Objectives of The Australian Prevention Partnership Centre

- Establish new ways for researchers, policy and program practitioners to work together and form strong national networks

- Produce internationally significant research about innovative methods in prevention, systems science and communication of prevention

- Help governments and the community better understand the importance of prevention

- Develop and provide tools and methods to support national prevention efforts

- Support increased capacity of researchers, policy makers and practitioners to use evidence and systems approaches in the design, implementation, evaluation and communication of prevention

- A broad set of objectives that go well beyond the production and translation of research and recognise that ongoing linkage and exchange between the producers and users of research is the key to its application and use in clinical practice, management or policy.

The Centre's innovative collaborative approach is attempting to bridge the divide between policy makers and practitioners and researchers. Researchers are working with policy makers and practitioners to develop research questions, conduct research, and analyse, interpret and disseminate the findings. As such, it is the model of interaction that is being tested as much as the specific projects. As well as undertaking new research, the Centre will look to collaborate with other research groups to better coordinate and connect Australia's chronic disease prevention research. This will include leveraging from research with others where this can more efficiently or effectively achieve the objectives.

The Centre is also aiming for a legacy of greater capacity among both practitioners and researchers for systems thinking about prevention. It has established four capacity units that will improve the gathering, sharing and use of evidence to build a prevention system in Australia (Box 2). The Centre will also create a structure to facilitate the uptake and use of the research findings, through researcher-policy maker partnerships in knowledge production, translation and application. We are developing new ways to systematically capture practice knowledge and synthesise it with evidence from research.

\section{The work program and initial priorities}

With our funding partners, we have developed plans for more than 30 projects over five years. Initial projects include:

- Examining how aspects of the Australian food supply affect availability, affordability and acceptability of different foods 
Box 2. Capacities of The Australian Prevention Partnership Centre

\begin{tabular}{ll}
\hline & Led by Professor Sally Redman \\
& at the Sax Institute, this unit \\
Synthesis & will develop and apply ways to \\
capacity & summarise and communicate \\
& evidence to address key issues for \\
& policy makers and practitioners.
\end{tabular}

Led by Professor Adrian Bauman at the University of Sydney, this unit will
Rapid response evaluation capacity estish and resource a system for embedding research and evaluation in the rollout of significant prevention policies and programs.

Led by Professor Alan Shiell at the Centre of Excellence in Prevention

Systems science and implementation capacity Science, this unit will bring a systems focus to all of the work of the Centre, and assist policy makers and practitioners to strengthen the design of interventions before and during implementation.

Led by Partnership Director Professor Andrew Wilson, this unit Communication capacity will develop methods to better communicate prevention issues and help develop a more sophisticated public dialogue on prevention science and public policy.
- Increasing the capacity of the prevention workforce to use systems thinking in developing and implementing strategies

- Developing methodologies to assess the adequacy of scale, intensity and quality of prevention interventions

- Developing and assessing options for national indicators for a prevention system, starting with indicators relevant to the built environment

- Developing ways to increase public understanding of prevention policy and science.

\section{Learning from practice and research}

A fundamental pillar of the Centre's approach is that public health practice and practitioners should inform prevention research as much as research should inform policy and practice. We will use a mixed approach to knowledge-to-action, which recognises that people and organisations in the preventive health system are at different stages and levels of familiarity with what might be considered 'more radical' approaches to knowledge (co-)production. ${ }^{17}$ This will involve three interlinked components:

- Establishing a model of engagement that will see policy makers, practitioners and researchers discuss problems and set research questions together, with variable levels of collaboration in the design and implementation of research and evaluation

- Developing a range of knowledge-exchange opportunities, from formal expert-led opportunities through to informal work-integrated, problem-based discussion

- Developing a model of knowledge production that maximises the likelihood that research will achieve its intended action.

To achieve this, we will facilitate opportunities for researchers to work in practice settings, and for practitioners to participate in research and evaluation. We will foster sharing of expertise and experience through practitioners and researchers working together on common problems - for example, changing the built environment or program evaluation - with input from experts drawn from the Centre's investigators or elsewhere.

\section{Conclusion}

The Australian Prevention Partnership Centre presents an opportunity for a new way to advance prevention science and practice. Our model brings together researchers, policy makers and practitioners to determine the information and actions needed for an effective prevention system for Australia. The research is as much in the process of the approach as in the focus and outputs of the specific projects.

Readers who are interested in the Centre's work are encouraged to visit the website at www.saxinstitute. org.au/our-work/preventing-chronic-disease or contact the Centre's Deputy Director, Associate Professor Sonia Wutzke, on (02) 91889555 or sonia.wutzke@ saxinstitute.org.au

\section{Acknowledgements}

The authors wish to acknowledge the contributions to this article of the Centre's investigators. The Centre is funded by the NHMRC, Australian Government Department of Health, NSW Ministry of Health, ACT Health and the HCF Research Foundation. It is administered and hosted by the Sax Institute, and co-hosted by the Centre of Excellence in Intervention and Prevention Science.

\section{Competing interests}

None declared. 


\section{References}

1. Australian Institute of Health and Welfare. Australia's health 2012. Canberra: Australian Institute of Health and Welfare; 2012.

2. Murray CJL, Vos T, Lozano R, Flaxman AD, Michaud C, Ezzati M, et al. Disability-adjusted life years (DALYs) for 291 diseases and injuries in 21 regions, 1990-2010: a systematic analysis for the global burden of disease study 2010. Lancet. 2012 Dec 15;380(9859):2197-2223

3. Australian Institute of Health and Welfare. Multiple causes of death in Australia: an analysis of all natural and selected chronic disease causes of death 1997-2007. Canberra: Australian Institute of Health and Welfare; 2012.

4. Australian Institute of Health and Welfare. Chronic diseases. Canberra: Australian Institute of Health and Welfare; 2012 [cited 2014 Sep 4]. Available from: www. aihw.gov.au/chronic-diseases

5. Australian Institute of Health and Welfare. Chronic disease and participation in work. Canberra: Australian Institute of Health and Welfare; 2009 [cited 2014 Mar 18]. Available from: www.aihw.gov.au/publicationdetail/?id=6442468211

6. Vos T, Carter R, Barendregt J, Mihalopoulos C, Veerman $\mathrm{JL}$, Magnus A, et al. Assessing cost-effectiveness in prevention (ACE-Prevention): final report. Brisbane: University of Queensland, Melbourne: University of Melbourne; 2010.

7. Australian Institute of Health and Welfare. Trends in cardiovascular disease. Canberra: Australian Institute of Health and Welfare; 2013 [cited 2014 Mar 21]. Available from: www.aihw.gov.au/cardiovascular-health/trends/\#t3

8. Australian Institute of Health and Welfare. Australia's health 2000. Canberra: Australian Institute of Health and Welfare; 2000 [cited 2014 Jul 11]. Available from: www. aihw.gov.au/publication-detail/?id=6442467153
9. O'Hara B, Phongsavan P, King L, Develin E, Milat A, Eggins $D$, et al. 'Translational formative evaluation': critical in up-scaling public health programmes. Health Prom Int. 2013;29(1).

10. Rychetnik L, Bauman A, Laws, R, King L, Rissel C, Nutbeam D, et al. Translating research for evidencebased public health: key concepts and future directions. J Epidemiol Commun H. 2012;66(12):1187-1192.

11. Milat A, King L, Bauman A, Redman, S. The concept of scalability: increasing the scale and potential adoption of health promotion interventions into policy and practice. Health Prom Int. 2013;28(3):285-298.

12. Steckler A, McLeroy, KR. The importance of external validity. Am J Public Health. 2008;98(1):9-10.

13. Livingstone MBE, McCaffrey TA, Rennie KL. Childhood obesity prevention studies: lessons learned and to be learned. Public Health Nutr. 2006;9:1121e9.

14. Antikainen I, Ellis R. A RE-AIM evaluation of theory-based physical activity interventions. J Sport Exerc Psychol. 2011;33:198e214.

15. Population Health Intervention Research Initiative for Canada. Ottowa: Canadian Institutes of Health Research; 2012 [cited 2014 Mar 20]. Available from: www.cihr-irsc. gc.ca/e/38731.html

16. National Health and Medical Research Council (NHMRC). NHMRC Partnerships for Better Health. Canberra: NHMRC; 2013 [cited 2014 Mar 18]. Available from: www. nhmrc.gov.au/grants/apply-funding/partnerships-betterhealth

17. Best A, Holmes B. Systems thinking, knowledge and action: towards better models and methods. Evid Policy. 2010;6(2):145-59.

\section{Copyright: 두)(요}

(C) 2014 Wilson et al. This article is licensed under the Creative Commons Attribution-NonCommercial-ShareAlike 4.0 International License, which allows others to redistribute, adapt and share this work non-commercially provided they attribute the work and any adapted version of it is distributed under the same Creative Commons licence terms. See: http://creativecommons.org/licenses/by-nc-sa/4.0/ 